\section{Poesia visual, \\ hipertexto e \\ ciberpoesia}

\section{RESUMO}

0 recorte deste trabalho limita-se à poesia visual e à poesia hipertextual. Os procedimentos dividiram-se em três fases: foram criados 28 poemas visuais, convergindo técnica e esteticamente 0 texto escrito com imagens do design, da pintura e outros tipos de desenhos. Foram escolhidos oito desses poemas visuais para serem retrabalhados hipertextualmente por diferentes profissionais. Realizou-se uma parceria com a W3haus para o desenvolvimento de um site e o planejamento de mais alguns ciberpoemas.

\section{ABSTRACT}

This article is a brief report on an experiment aimed at developing new forms for visual poetry in cyberspace. The authors developed a site with the help of a professional cyberstudio (W3haus), to explore new modes of artistic expression in the Web, mixing concrete poems with digital illustrations and animation design.

\section{PALAVRAS-CHAVE (KEY WORDS)}

- Ciberpoesia (Cyberpoetry)

- Hipertexto (Hypertext)

- Novas tecnologias (New technologies)

Sérgio Capparelli

Prof. Dr. do PPGCOM da FABICO/UFRGS

Ana Cláudia Gruszynski

Prof. Mestre da FABICO/UFRGS

GilbertoKmohan

Mestrando do PPGCOM/ UFRGS

\section{Introdução}

EM UM TEXTO muito citado, o antropólogo Clifford Geertz discute a impossibilidade de se querer compartimentar certos gêneros já que eles apresentam-se de forma blurred (Geertz, 1977). O substantivo blur e o adjetivo blurred servem para explicar esse momento de transição dentro da Antropologia em que as fronteiras entre gêneros tornam-se nebulosas, obscuras, ou híbridas, sendo, ao mesmo tempo, isso e aquilo. Talvez seja um sinal de novos tempos, pois este fenômeno não acontece apenas dentro das Ciências Humanas. Um livro recente de Christopher Meyer e Stan Davis, intitulado Blur: The speed of change in the connected economy, vai discutir precisamente a fusão ou hibridação dos setores das telecomunicações, da informática e multimídia (Meyer \& Davis, 1997).

Aproximações, fusões ou distanciamentos são comuns dentro das Ciências Sociais e Humanas. Basta ver a ramificação da Filosofia na Grécia e a miríade de campos especializados, hoje, originários da mesma árvore do conhecimento, se tomados num corte diacrônico. Mas o que têm a ver os blurred genre de Geertz ou o Blur: The speed of change, de Meyer e Davis, com imagem e escrita nas hibridações ora propostas? $\mathrm{O}$ primeiro exemplo mostra que o fenômeno não é exclusivo das artes, nem é recente, e o segundo indica que se a multimídia converge com outros campos - informática e telecomunicações -, o poema eletrônico, experiência analisada na terceira seção deste trabalho, sofrerá influências dessas convergências.

Vamos por partes, no entanto, tentando mostrar que o ideal de uma arte abrangente, reunindo técnicas e tecnologias diversas de expressão, revela tensões dentro e fora da área. Pretende-se, aqui, descrever 
e analisar algumas dessas tensões, bem como algumas das trajetórias dessas mesmas tensões, especialmente aquelas que dizem respeito à (1) hibridação da linguagem verbal e não-verbal com o uso de tecnologias tradicionais (imagem e escrita) e (2) hibridação da linguagem verbal e não-verbal a partir das novas tecnologias (imagem sintética e escrita eletrônica).

$\mathrm{O}$ recorte limita-se à poesia visual e à poesia hipertextual (aqui com a denominação de ciberpoesia). Os procedimentos dividiram-se em três fases: para a primeira, foram criados 28 poemas visuais, convergindo técnica e esteticamente o texto escrito com imagens do design, da pintura e outros tipos de desenhos. Na segunda fase, foram escolhidos oito desses poemas visuais, a fim de serem retrabalhados hipertextualmente por diferentes profissionais. Na terceira, realizou-se uma parceria com o cyberstudio W3haus para o desenvolvimento do site (www.ciberpoesia.com.br) e o planejamento de mais alguns ciberpoemas.

Passou-se, então, a uma reconstituição dos procedimentos, baseada na poética segundo conceito de Umberto Eco, que fala na necessidade de se comparar o plano inicial do trabalho poético em relação ao produto final, ou seja, "o projeto de formação ou de estruturação de determinada obra" (Plaza \& Tavares, 1998:120).

$\mathrm{Na}$ introdução à segunda edição de sua Obra Aberta, Eco sugere que há diversos objetivos no estudo das poéticas, mas que o juízo crítico é quem vai verificar se as várias obras cumpriram ou não o projeto inicial. Neste sentido, ele faz uma ressalva: "O que nos interessa é esclarecer os projetos de poética para iluminarmos através deles (inclusive quando dão lugar a obras malogradas ou discutíveis do ponto de vista estético) uma fase da história da cultura" (Eco, 1986:25). E um dos caminhos para chegar a esse objetivo são depoimentos dos artistas ou a própria análise da obra, para revelar sua gênese, desvios, caminhos percorridos e pontos de chegada.

Esta reflexão tem como pano de fundo a preocupação constante dos artistas em busca de uma arte mais abrangente, a começar por Lautremont que afirmou, em 1860 , que a poesia deveria ser feita por todos e não apenas por um; pelos dadaístas, especialmente os do Café Voltaire, de Zurich, e do grupo de Berlim; pelos futuristas de Marinetti; pelos concretistas alemães, japoneses, suíços e brasileiros; pela revolução eletrônica de Burroughs; e, mais recentemente, pelos experimentalismos poéticos viabilizados pelo hipertexto. Começaremos, na próxima seção, precisamente com esses antecedentes.

\section{Imagens e palavras em liberdade}

A vanguarda, segundo Bürger (Bürger, 1974), é a crítica ao princípio romântico da imediatez e da transparência do sentimento característico do Expressionismo. Com ela se inaugura uma concepção em que a arte não é mais um meio para difundir ou expressar emoções ou juízos alheios aos processos da sua realização. A arte é, ela mesma, parte constitutiva da realidade. A idéia de sistema, essencial ao Classicismo, é abandonada pois não se trata, aqui, de organizar realidades existentes, mas de provocar a emergência de realidades implícitas. Daí que a realização plena da vanguarda seria não o momento crítico, porém o construtivo. Essa busca leva ao recalque das convenções da natureza e do uso do material artístico: como o figurativo nas artes plásticas e o tonalismo na música.

Quando Schoenberg assume a negação do princípio tonal e converte em material a assonância, não a converte em princípio ontológico, mas recusa a ornamentação e eleva a arte à dignidade de uma forma de conhecimento. A vanguarda, enquanto ruptura epistemológica, somente adquire sentido enquanto não separarmos projeto estético e pensamento teórico. Os seus atributos físicos são categorias: o princípio construtivo, a abstração e a ambigüidade atestam a intensidade de princípios estéticos ir- 
redutíveis ao controle da prática artística. Entretanto, somente nela encontram a plenitude do seu sentido. Enquanto recusa radical da representação, a vanguarda renuncia a qualquer tradução alheia ao seu universo. A desfiguração sofrida pela mimesis assinala a construção da forma através de relações conceituais e não de unidades físicas.

A procura por um equilíbrio entre as diversas manifestações artísticas e a rejeição da mediação da escrita na poesia e na prosa constitui uma das facetas da vanguarda. Essas tentativas têm no Futurismo o seu laboratório de experiência. Os artistas passam a buscar as outras dimensões da poesia, perdidas com a divisão dos gêneros artísticos através da tecnologia da escrita. Os tipos e as letras passam a ser aceitos em sua materialidade: o som, com a busca do dinamismo dos objetos; o peso, com o reconhecimento da qualidade de voar inerente aos objetos; o odor, com a faculdade dos objetos de se dispersarem. As palavras devem existir em liberdade e não presas ao procedimento linear, fixadas pela sintaxe e pelas convenções gramaticais. $\mathrm{O}$ tipo e a escrita libertam-se da opressão de serem meros suportes de sentido.

A escrita, que no livro impresso havia encontrado um asilo onde levava sua existência autônoma, é inexoravelmente arrastada para as ruas pelos reclames e submetida às brutais heteronomias do caos econômico. Essa é a rigorosa escola de sua nova forma. Se há séculos ela havia gradualmente começado a deitar-se, da inscrição ereta tornou-se manuscrito repousando oblíquo sobre escrivaninhas, para afinal acamar-se na impressão, ela começa agora, com a mesma lentidão, a erguer-se novamente do chão. Já o jornal é lido mais a prumo que na horizontal, filmes e reclames forçam a escrita a submeter-se de todo à ditatorial verticalidade. $\mathrm{E}$, antes que um contemporâneo chegue a abrir um livro, caiu sobre seus olhos um tão denso turbilhão de letras cambiantes, coloridas, conflitantes, que as chances de sua penetração na arcaica quietude do livro se tornaram mínimas (Benja- $\min , 1980: 102)$.

O Dadaísmo marca, segundo Dachy (1994), um divisor de águas na concepção da obra de arte. A impaciência frente à compartimentação da arte não era somente, como nos futuristas, a expressão de um gesto que se diluía na experimentação estética. Segundo Ball: "Com a diluição das fronteiras entre as artes, o pintor voltava-se para a arte da poesia, e o poeta dedicava-se à pintura. Em toda a parte refletia-se a ilimitação" (Richter, 1993:70). A fragmentação dos gêneros, típica dos procedimentos acadêmicos, era a comprovação da falência do pensamento compartimentado da $A u$ fklärung. Tristan Tzara definia o movimento como um état d'esprit: Dada, um nome absurdo para um mundo absurdo. O Dadaísmo era especialmente atento aos benefícios terapêuticos do instintivo, do ilógico, do escandaloso. A arte transforma-se na negação da arte: as exposições eram organizadas para terminarem em chahuts. A revolta Dada contra a totalidade da herança européia é resumida na reprodução da Gioconda de Leonardo da Vinci por Marcel Duchamp: com barba, bigode e legenda obscena. A revolta contra a tradição é revolta contra as imposições do raciocínio linear, do princípio da não-contradição. "Na extinção do dualismo revela-se a natureza deste movimento. Pretendia-se que o pensamento fosse ampliado, que se integrassem pensamento e sentimento, sentimento e pensamento, e que ambos se fundissem no poema, na imagem, no som" (Richter, 1993: 73).

O exemplo mais claro do que aqui nos interessa foi a publicação, no outono de 1913, do poema verbo-visual La Prose du Transsibérien et de la petite Jehanne de France, fruto da colaboração do poeta Blaise Cendrars e da pintora Sonia Delaunay. Perloff descreve-o como uma única folha de papel, dividida ao meio, que se desdobrava como um acordeão em vinte e dois painéis, numa extensão de mais de dois metros de altura.

À esquerda, um painel que contém a página de rosto inicia a passagem do olho para baixo, através de uma seqüência de 
formas visuais semi-abstratas em brilhantes cores primárias, até um painel final que contém uma imagem infantil da Torre Eiffel, um curiosamente inocente falo vermelho gigante que penetra uma Grande Roda laranja com um centro verde. À direita, entrementes, o texto do poema é prefaciado por um mapa da estrada de ferro do Guia Michelin que mostra a viagem do Transiberiano de Moscou ao Mar do Japão; na parte inferior desse mapa, uma larga faixa verde introduz o título do poema em grandes letras de fôrma, como se o pochoir fosse o letreiro de um cartaz. Segue-se então o texto, composto em blocos sucessivos de diferentes tipologias, quebrados por grandes planos irregularmente formados e de cores predominantemente pastel (Perloff, 1993: 32).

Neste experimento, o poema-pintura assume a disposição de uma espécie de cartaz de propaganda. A transformação da página convencional é um recurso consciente de Cendrars: a publicidade é, para ele, o "mais caloroso sinal do vigor do homem de hoje - na verdade uma das sete maravilhas do mundo" (Perloff, 1993:41). Deste modo, a estratégia utilizada é voltar o desgaste da linguagem ocasionada pelas mídias contra a própria linguagem.

Contra o engessamento da linguagem, a natureza construtiva da vanguarda determina sua tendência à abstração. Nas artes plásticas a composição clássica se fundamentava nas idéias de hierarquia e totalidade. Seu método era a unidade como totalidade. Sua referência a mimesis. A vanguarda parte de uma idéia fragmentária da unidade. A estrutura é imanente, não excede o âmbito da obra e questiona sua materialidade enquanto objeto. Em 1928, Paul Klee reage à ilegibilidade da realidade através da construção de uma arqueologia dos signos urbanos. O resultado desse experimento é a tela Ein Blatt aus dem Städtebusch. Nela, procura elaborar através da imaginação poética uma aliança com a realidade externa. As formas da cidade esfumam-se, desprovidas de profundidade, fixadas na superfície plana de um livro, através de formas geométricas, sobriedade cromática, abstração e esquematismo. A escritura invade e explode a convenção pictórica, lembrando a escrita cuneiforme. A cidade torna-se resíduo, palimpsesto, texto. Como texto, a cidade é a reunião fragmentária de uma outra cidade e, ao mesmo tempo, a mesma. Registrar a escritura da cidade é não somente consignar e transcrever, mas, também, reter na memória. O texto é o relato sensível das formas de ver a cidade; não enquanto mera descrição física, porém como a cidade simbólica, que cruza lugar e metáfora, produzindo uma cartografia dinâmica, tensão entre racionalidade geométrica e emaranhado de existências humanas.

A abstração da forma ancora-se em relações de conceitos e não em hierarquias de elementos. A renúncia à totalidade como referência estrutural e da unidade como garantia de identificação está vinculada ao fundamento espacial da sua própria natureza. O espaço, enquanto entidade física, é o suporte da forma enquanto termos relacionais mas, também, índice do abandono da temporalidade como dimensão da sua existência.

$\mathrm{Na}$ música e nas artes plásticas, a idéia de sucessão temporal é substituída pela simultaneidade de silêncios no espaço. A estética de Mondrian tem como pressuposto esta suspensão: a simultaneidade é a condição necessária da disposição pictórica e atributo essencial da forma. Em 1897, com a publicação do poema Un coup de dés, Mallarmé havia antecipado o princípio estético do silêncio. Com este poème typographique et cosmogonique, segundo $\mathrm{Au}$ gusto de Campos, é inaugurada a poesia moderna.

Mallarmé é o inventor de um processo de organização poética cuja significação para a arte da palavra se nos afigura comparável, estéticamente, ao valor musical da "série", descoberta por Schoenberg, purificada por Webern, e, através da filtração deste, legada aos jovens compositores eletrônicos, a presidir os universos sonoros de 
um Boulez ou um Stockhausen. Esse processo se poderia exprimir pela palavra estrutura. Acrescentemos que o uso particular, que aqui fazemos, da palavra estrutura, tem em vista uma entidade medularmente definida pelo princípio gestaltiano de que o todo é mais que a soma das partes, ou de que o todo é algo qualitativamente diverso de cada componente, jamais podendo ser compreendido como um mero fenômeno aditivo (Campos, 1974:177).

Não é por acaso que os concretistas consideram Mallarmé como um dos seus predecessores. As manifestações objetivas da nova organização do verso são a contraposição à organização linear e aditiva do verso tradicional e o dinamismo do processo de associação de idéias. A idéia de estrutura repousa sobre esta dupla metamorfose. No Préface a Un coup de dés faz-se explícita a exigência de uma tipografia funcional que espelhe as metamorfoses, os fluxos e refluxos das imagens: emprego de tipos diversos; a presença de "brancos" como espaço do silêncio; o uso especial da página, onde as palavras formam um todo e ao mesmo tempo se separam em dois grupos, à direita e à esquerda da prega central. Através desse processo o poema torna-se ideograma. As subdivisions prismatiques de l'idée mallarmeana constituem o processo de composição em que duas coisas isoladas criam uma terceira sem relação entre elas.

A poesia concreta, através dessa concepção, cria um "novo conceito de composição - uma ciência de arquétipos e estruturas; para um novo conceito de forma uma ORGANOFORMA- onde noções tradicionais como início, meio, fim, silogismo, tendem a desaparecer diante da idéia poético-gestaltiana, poético-musical, poéticoideogrâmica de ESTRUTURA" (Campos, 1974: 186).

A noção de estrutura permite a possibilidade da construção de poemas sem signo verbal, somente com imagens. Segundo Solt (1999), as pretensas funções não-lingüísticas são a maneira em que se manifes- ta o caráter semântico da palavra.

O poeta concretista está preocupado em produzir um objeto para ser percebido mais do que para ser lido. Os poemas visuais são para serem vistos como pintura; os poemas sonoros são compostos para serem ouvidos como música.

Os poetas concretistas, então, estão unidos em seus esforços para construir objetos ou composições de sons de materiais particulares; mas estão desunidos na questão semântica: alguns insistem na necessidade da poesia ficar dentro da área da comunicação semântica e outros convencidos de que a poesia é capaz de transmitir novas e outras formas de informação - puramente informação estética (http://www.ubu.com/papers/ solt/intro.html).

A divisão da poesia concreta em três grandes tendências mostra que, de um lado, ela separa-se daquela puramente verbal e, do outro, no seu conjunto abarca tanto o movimento como o visual e o sonoro.

O poema sonoro será definido por Solt (1999) como a "sucessão auditiva" na qual "a figura (som) irrompe do silêncio produzindo a configuração do tempo cheio contra o tempo vazio". Sua forma serial é freqüentemente vista como relacionada com as formas seriais estruturais do modelo linear da poesia tradicional.

O poema cinético é a "sucessão visu$\mathrm{al}^{\prime}$ ", na qual "as dimensões da figura visual são estendidas para produzir uma configuração temporal somente possível pelo sentido da sucessão".

O significado é revelado gradualmente, o método serial "substitui a gramática discursiva" e, deste modo, o "uso da poética, sem os suportes das formas faladas ou escritas familiares, produz um tema exclusivamente artístico". O poema visual é uma "constelação" no espaço.

Esta forma poética levanta uma questão fundamental: sendo o poema visual uma "constelação no espaço, o senso da simultaneidade e de multidirecionalidade uma ordem espacial - inibe a resposta fonética na seqüência às unidades verbais". 


\section{Poesia visual}

Cada vez mais se discute se estamos na galáxia de Marconi e se deixamos para trás a galáxia de Gutenberg. Ou se entramos na civilização da imagem e deixamos a civilização da escrita. A afirmação tem origem nas mudanças que o mundo presenciou neste século, principalmente com a televisão como mídia hegemônica na passagem do século. Essas mudanças foram tão rápidas que se insiste, na área acadêmica, em uma área de conhecimento específica a merecer a atenção, ou seja, a da cultura visual. "Muitos teóricos do pós-modernismo concordam que um de seus aspectos distintivos é o predomínio da imagem. Com a ascensão da realidade virtual e da Internet no ocidente, combinado com a popularidade globalizada da televisão, videoteipe e filme, essa orientação parece continuar" (Mirzoef, 1999: 90). Para Mirzoef, no entanto, não se trata apenas de uma constatação que tem fim em si mesma, mas a aceitação de um postulado que envolve a trajetória de hostilidade a respeito da imagem, de Platão a Bourdieu, passando por Jameson, marcando o pensamento ocidental.

Essa tensão entre os campos da escrita e da imagem - esta última quase sempre em posição subordinada - certamente sofre as influências da passagem da chamada civilização da escrita para o predomínio atual da imagem. O campo do design é certamente um bom exemplo dessas tensões e dessas mudanças de perspectiva. Giovannini, um dos autores que defendem esse predomínio da imagem e do design sobre a escrita, assim se expressa:

“(...) em um livro ou numa revista, um meio ambiente ecológico de palavras, imagens, padrões gráficos, seqüências, espaço e espaçamento - um equilíbrio delicado que faz a publicação legível. Mas legibilidade nem sempre é o ponto principal. Muitas publicações provêm, em vez disso, uma espécie de ambiente perceptivo, usualmente divertido, no qual os leitores tornamse espectadores experimentando as tensões visuais das páginas diagramadas mais pelo estilo que pelo conteúdo. Cada página, como um pôster, tem sua própria consistência. A revista, em particular, é uma galeria manual." (Giovannini, 1988: 201)

A seguir, ele afirma que a conseqüência do design em muitas publicações é, então, a fragmentação ou subordinação do texto (Giovannini, 1988: 204). Ou ainda, o gráfico, 'liberado' pela nova fotografia e pelas tecnologias do computador e forçado pela competição com a televisão, o videoteipe e outros mídias não impressos, visando ao entretenimento, está ameaçando tanto o texto como a fotografia. Ele adianta que "o design da página, misturando e cortando palavras, fotografias e padrões gráficos, de forma livre e agressiva, levando à criação mais de uma página de design do que uma página de texto" (Giovannini, 1988: 201).

Vai mais longe, citando a diretora de arte da revista Metropolis, Helene Silverman, para quem ler uma revista pelo seu design é tão válido como lê-la pelo seu conteúdo (Silverman apud Giovannini, 1988: 202).

Estamos diante de uma revanche da imagem e do design sobre a escrita? Para alguns, como Giovannini, sim, quando fala na "capitulação do texto para o layout", que pode ser visto em livros de artes plásticas, nos quais os textos são muitas vezes tratados mais como blocos visuais, vassalos das fotografias. E também quando aparentemente busca uma retórica desabusada e aponta essa tensão num espaço mais políti$\mathrm{co}$, indiretamente quebrando um ar determinista de novas e antigas tecnologias:

"A batalha é antes de tudo entre a cultura verbal e a cultura visual, entre aqueles que têm sido chamados "word people" e os "image people", entre aqueles - já há algum tempo - intelectuais da Partisan Review e outros, do Departamento de Design do Museu de Arte 
Moderna de Nova Iorque. (...) Hoje, a linha daquela batalha pode ser encontrada entre os editores do The New York Review of Books e os designers gráficos e de cenários da MTV." (Giovannini, 1988: 204-205)

Há quem evite tanto a linguagem como a crítica radical e procure ver essas relações entre a imagem e a escrita numa perspectiva histórica, especialmente entre aqueles que pretendem explicar essas expressões através das tecnologias adotadas.

Essas periodizações apontam, geralmente, três períodos de expressão, tendo a fotografia como eixo modulador: período pré-fotográfico, fotográfico e pós-fotográfico.

Mirzoeff (1999) divide sua introdução à cultura visual em três capítulos, cada um referindo-se no título a um desses períodos: o da imagem tradicional, simbolizada pela pintura; o da fotografia propriamente dita; e o da morte da fotografia, com o surgimento da imagem virtual.

Entre nós, Santaella aborda a evolução histórica da produção de imagens segundo três paradigmas: (1) o pré-fotográfico, que engloba os tipos de imagens artesanais, desenho, pintura, gravura, etc.; (2) o fotográfico, que se refere às imagens que pressupõem uma conexão dinâmica entre imagem e objeto, imagens que, de alguma forma, trazem o traço, rastro do objeto que elas indicam - essas imagens se estendem da fotografia, cinema, tv e vídeo até a holografia; (3) o pós-fotográfico, que designa as imagens sintéticas ou infográficas, imagens que são inteiramente calculadas por computação (Santaella, 1998: 167).

Para ela, a passagem histórica de um paradigma a outro não se dá nunca de modo abrupto, quer dizer, há fatores de mudanças que chegam a caracterizar fases mais ou menos longas de transição entre um paradigma e outro. Outro aspecto, é o da mistura entre os paradigmas, acasalamentos e hibridação de linguagens.

Julio Plaza também trata dessas três fases: a gravura e a imprensa, que, no sécu- lo XV, estabelecem as condições para a difusão de imagens; a fotografia, posteriormente, que mecaniza a reprodução da imagem, mas também o próprio produto; e agora, quando se passa do mecânico ao eletrônico - "assim, depois das imagens de tradição pictórica, das imagens pré-fotográficas e das imagens fotoquímicas (foto e cinema), surgem as imagens de terceira geração, ou seja, as chamadas imagens de síntese, as imagens numéricas, as imagens holográficas" (Plaza, 1988: 72).

Essas periodizações, no entanto, mesmo que estabeleçam princípios explicativos comuns, precisam levar em conta que um novo período - ou instauração de novo paradigma, no dizer de Santaella (1998) não significa a supressão dos anteriores. Partindo do princípio de que cada novo período não acontece sobre uma tábula rasa, multiplicam-se resíduos dos períodos anteriores, fazendo com que, em um único país, comunidades ainda vivam no período da civilização da imagem rupestre, enquanto outros, a centenas de quilômetros, operem os suportes da imagem digital. $\mathrm{O}$ que se vê, sobretudo, nessa superposição de paradigmas, é uma linguagem visual marcada pela hibridação. Santaella apreende bem essa imbricação de fenômenos, essa mistura de elementos de períodos diferentes.

Ilustração dessas misturas pode ser encontrada nos fenômenos artísticos que receberam o nome de hibridação das artes e que, contemporaneamente, comparecem de modo mais cabal nas instalações, onde objetos, imagens artesanalmente produzidas, esculturas, fotos, filmes, vídeos, imagens sintéticas, são misturadas numa arquitetura, com dimensões, por vezes, até mesmo urbanísticas (Santaella, 1998: 175).

Ou, na seqüência da argumentação da autora, quando explica que a fotografia importou procedimentos pictóricos, ao mesmo tempo que a pintura muitas vezes adquiriu traços estilísticos que vinham da fotografia. Assim, também, a computação gráfica herdou caracteres plásticos da pintura e, evidentemente, da fotografia, ao 
mesmo tempo em que veio produzir uma verdadeira revolução no mundo da fotografia (Santaella, 1998:175). Essa coreografia de períodos que se interpenetram, campos que se entrecruzam vão influir, também, no fazer poético.

Podemos visualizar isso no poema visual $O$ Navio que foi desenvolvido na primeira fase deste trabalho. Ele possuía um layout preliminar e foi tratado no plano da linguagem verbal tendo em vista a consistência entre imagem/texto. Partiu de uma composição original do designer Saul Bass mostrando um navio a vapor sobre um mar escuro. A fumaça saindo pela chaminé eram feixes de letras, que formavam palavras, ao acaso, sem uma sintaxe clara. O navio podia estar chegando ou partindo. Pela posição, a partir de seu eixo, iria cruzar a qualquer momento diante dos nossos olhos, numa suave diagonal.

De posse dessa imagem, fizemos um primeiro esboço, transpondo a imagem do navio para um poema, utilizando-nos da linguagem verbal. As linhas principais deste esboço podem ser encontradas no trabalho final, sem grandes alterações. $\mathrm{Na}$ busca dessa linguagem híbrida, deduzimos que página deveria ser construída não apenas como um diálogo entre linguagens mas, principalmente, como um solilóquio verbal/não-verbal. Diante do quadro, apenas esboçado, eram evidentes quatro elementos fortes: o mar, o navio, a fumaça e o céu, constituído pelo fundo branco da folha de papel.

No fim, tínhamos uma página, formato A4, com a imagem do navio, que poderia estar se distanciado ou chegando a um porto. Este porto não eram os olhos do leitor, pois o navio passava pela página, em diagonal. Um quarto dela era constituído de um mar azul, com a superfície em linha reta. Da chaminé continuava saindo a fumaça, feita e refeita, porque os evocavam a idéia de fumaça, de algo em transformação. Para reforçar isso, o bloco do texto (que trabalha com proximidade e similaridade para conduzir a impressão de conjunto) também está em movimento. Assim, ficamos com três elementos: a imagem do mar, do navio (em diagonal), sua silhueta contra um fundo branco. O conjunto empurrava a superfície da página para a visão do espectador, criando esse tipo de imagem que faz parte do âmbito imaterial, onde a imaginação, os esquemas mentais, as visões, têm seu lugar (Santaella \& Nöth, 1997).

Voltando-nos novamente a idéia de $O$ Navio, é fundamental apontar a questão de sua leitura como um procedimento do todo para as partes (top-down), uma vez que o valor de cada elemento integrante do layout só pode ser avaliado tendo em vista a totalidade da imagem (cf. Aumont, 1995: 68; Arnheim, 1996:4; Santaella \& Nöth, 1997: 50). Em outras palavras, a visão lançada sobre a página de $O$ Navio mostra nitidamente a embarcação sobre o mar azul, mas onde, só examinado no detalhe, se revelará o caráter minimalista da construção visual. A própria manipulação na imagem da embarcação reforça essa falta de nitidez, deixando à visão construir o todo. Essa apreensão do todo, em primeiro lugar, se confirma quando a visão aproxima-se da fumaça e, ao aproximar-se, salta do paradigma da linguagem não-verbal para cair nos versos sinuosos em sua materialidade, sinuosos na sua conformação e rítmicos no seu movimento, tanto no verbal quanto no não-verbal.

E tem-se a sensação de que este mesmo quadro branco e azul, com uma embarcação etérea, em negro, nunca terá a mesma aparência sob um fundo de outra cor. Luminosidade, bordas e cores não são gerados de modo isolado, mas simultâneo, e a percepção de um elemento afeta a dos outros, pois a forma do navio se casa com sua cor e com outras cores, com sua forma e outras formas. Não temos, portanto, um código visual válido em qualquer configuração: "Koch (...) define planos de articulação da imagem, que vão, analogamente à linguagem, de unidades mínimas distintivas até o plano do texto, mas que devem ser, por outro lado, definíveis em seu valor somente no quadro de uma única imagem" (Santaella \& Nöth, 1997: 51). 


\section{Os ciberpoemas}

Do poema visual para o ciberpoema houve um grande caminho. Abria-se, ali, um espaço para a comprovação do que tinha sido apenas sugerido por diversos autores: o computador permite a realização da Gesamtkunstwerk sonhada por Richard Wagner (http://users.utu.fi/hansalmi/texts/benennun.html) e pelas vanguardas.

Essas combinações de todos os media computers a nossa disposição são uma síntese de todos os outros meios eletrônicos prévios e também podem combinar texto e qualquer coisa que possa ser digitalizada. Conseqüentemente, sua primeira herança e forma vêm de artes que existiram previamente, não dos paradigmas contemporâneos. Ferramentas não são acessórios que manipulamos para nossos fins, mas conformam e circunscrevem o leque de nossas direções e expressões (Andrews, 2000).

A partir dessas novas tecnologias as experimentações poéticas tomaram diversos rumos. Podemos citar alguns deles, a partir de uma navegação exploratória por alguns sites, tomados ao acaso:

1. Galerias e coletâneas em rede: as que levam a blocos de textos ou a galerias, mais especificamente com poemas visuais. A galeria de poesia concreta da Universidade de Búfalo, nos Estados Unidos, é um exemplo desta tendência (http://wings.buffalo.edu/epc/ gallery).

2. Fábrica de poemas: autores como Burroughs, Queneau e o grupo Oulipo (Ouvroir de Littérature Potentielle) foram perseguidos pelo mesmo sonho de Mallarmé, dar forma a "um livro integral, um livro múltiplo que contivesse potencialmente todos os livros possíveis" (Machado, 1996:165). Essas fábricas, ou melhor, esses geradores de poemas a partir de programas de computadores multiplicam-se. Como exemplo, indicamos duas fábricas de hai-kais, algumas exigindo o trabalho do leitor na linha de montagem dos poemas (http://www.sfc.keio.ac.ip/ >yukihiko/haiku.shtml e http://www.ArtCommotion.com/cgi/haiku.pl.20-20-20). As leituras dos produtos desses geradores lembram algumas experiências dadaístas em que o aleatório era um componente importante da poética.

3. Poesia sonora: alguns sites de poesia sonora retomam experiências do Futurismo de Marinetti e do Dadaísmo de Hugo Ball. Ao discutir a importância da poesia oral, Menezes evoca McLuhan: a perda da hegemonia do texto linear e a divisão de sentido imposta pela linguagem verbal leva à relevância cada vez maior que a audição e a comunicação vocal tem nos dias de hoje: "Este é, portanto, um panorama que reforça aquele ponto de vista central que retira do texto a poeticidade e a entrega a uma voz que revigora a integridade dos sentidos e o corpo" (Menezes, 1998: 273). Exemplo: http://wings.buffalo.edu/epc/gallery.

4. Poesia declamada: sites em que, por exemplo, um ator ou o próprio poeta lê seus poemas (http://www.ubu.com). A revista Slate da Microsoft tem uma página de poesia, com o texto, e, em off a voz do autor: $h t t p: / /$ www.slate.com/cover.asp.

5. Nova poesia visual: experimentos que vão além da visualidade tradicional e criam poemas visuais em três dimensões. Alguns autores tornam-se adeptos da poesia visual através da literatura e outros através das artes plásticas. Exemplo: http://student.uq.edu.au/ s271502/work.html

6. Poesia cinética: gênero poético em que são criadas animações em poesia através de técnicas variadas. Pode se tratar de imagens cinéticas, mas, especialmente de tipos, às vezes de corpos diversos, que se movimentam na tela do computador. A poesia cinética usa a palavra enquanto objeto arquitetônico e desenho, numa materialidade capaz de se locomover, criando espaços de tensões ou de harmonias. Exemplo: http://student.uq.edu.au/ s271502/work.html e 
http://www.vispo.com/animisms/SeattleDrift.html

Esses sites utilizam o que George Landow chama de modelo não-linear, aquele que utiliza o hipertexto, tanto em ficção quanto em poesia. Neste modelo, os textos impressos são transferidos ao hipertexto e tomam a forma de blocos, nós ou lexias, unidos em uma rede de nexos e trajetos (Landow, 1995:37 e http://landow.stg.brown.edu/cpace/ ht/htov.html).

Alguns autores criticam a noção de não-linearidade, preferindo multilinearidade (Cf. Capparelli e Longhi, 1999: 24-41 e Aarseth, E., 1997 e Palácios, 1999). Os ciberpoemas aqui propostos seguem este modelo multilinear.

Dentro do tema aqui abordado, interessam-nos as experiências que representam a convergência da linguagem verbal, da imagem (fixa e móvel) e do áudio na poesia. Estamos nos referindo, portanto, à poesia hipertextual que se apresenta

“(...) como uma matriz de números em filas e colunas, na memória do computador. Seus números e pixels podem ser alterados e manipulados, individualmente ou em grupos, e o conjunto pode ser traduzido na forma de imagens no monitor de tv ou, inclusive, em forma impressa. Qualquer modificação na matriz de números implica uma modificação na imagem. (...) Tratam-se, pois, de imagens conceituais, produtos da sintaxe do computador, puras estruturas." (Plaza, 1998: 73)

Júlio Plaza indica que a diferença entre a imagem nos períodos fotográfico e pós-fotográfico é que, neste último, as imagens, típicas da gravura, da fotografia, do cinema, se confundem com seus suportes: "A rasura da mensagem comporta a rasura do suporte" (Plaza, 1998: 75). Além dessa imaterialidade da imagem, ele aponta a interatividade possível, a hibridação de linguagens de que falava Santaella (1998), com as imagens televisivas, computadorizadas, digitalizadas ou holografadas. Incorporando os caracteres de seu meio e modificando as formas tradicionais de produção de imagens (Plaza, 1998: 75).

O ciberpoema Zigue-zague foi construído como uma narrativa interativa. Podemos dividi-lo em três partes: (1) apresentação do título do poema e das personagens; (2) construção do poema segundo versos/design estabelecidos na versão impressa; (3) frame a partir do qual se abre a possibilidade de interagir com o poema através das opções dispostas em links (que se tornam disponíveis apenas depois da segunda parte).

$\mathrm{O}$ termo interatividade refere-se aqui à interação técnica que pode se estabelecer entre homem-máquina de modo analógicomecânico e eletrônico-digital - níveis não excludentes. O usuário, além de interagir com a máquina (interação analógico-mecânica), pode também interagir com o conteúdo do hipertexto, com a informação. Nesse âmbito, situa-se também a discussão sobre interface, ou seja, a zona de contato entre o homem e a máquina, onde se articulam os espaços de comunicação entre realidades distintas, entre sistemas que não utilizam a mesma linguagem (cf. Lemos, 2000).

Paralelamente as partes indicadas acima, podemos estabelecer também três níveis que levam em conta o feedback entre o leitor e o ciberpoema. São eles: (a) o que concerne ao hardware; (b) ao browser que está sendo utilizado para visualizar o documento; (c) aquele relativo ao hipertexto Zigue-zague em si mesmo.

As ações em que o leitor manipula os dispositivos de entrada dizem respeito ao hardware e envolvem as possibilidades que o usuário tem de acionar o teclado, o mouse, etc. No caso do ciberpoema que estamos analisando, elas são disparadas essencialmente pelo mouse, e outros recursos estão disponíveis através de comandos dos programas de visualização (browser) e gerenciamento (sistema). Uma vez que Zigue-zague foi programado em Macromedia Flash, necessitamos de versão atualizada do browser 
utilizado, bem como o plug-in Shockwave que permite a navegação por todas as potencialidades previstas pelo programador. Com isso, as opções visuais determinadas a partir do browser não são praticamente utilizadas, o que garante que o navegador verá (espera-se) aquilo que o web designer planejou.

Quanto ao último nível, o ciberpoema possui em si mesmo todos os recursos necessários para a navegação através dele. Sua interface gráfica - modelo interativo que envolve sistemas que trabalham sobre os indicativos de tela baseados em janelas (windows), ícones, menus e ponteiros compreende um jogo entre frames que se seguem em uma janela principal. Nas duas primeiras partes, conforme apresentado anteriormente, o leitor pode apenas "assistir" à seqüência de frames (pensando aqui nos recursos do próprio hipertexto).

Ao ingressar no ciberpoema, o navegador é levado (já que não pode ainda interagir) a um mergulho. Contribuem para isso o título que se movimenta simulando estar boiando na água, as bolhas que saem do fundo e desaparecem no topo da janela, as personagens que saltam de um lado a outro do mar ao serem apresentadas, o barulho das ondas e das gaivotas, as letras que formam o corpo dos peixes (as escamas?), os versos que parecem sair de dentro de nossos olhos para delinear o corpos de Zig e Zag (as personagens). Todas essas imagens vão envolvendo o leitor e o imergindo nas possibilidades de sentido de $\mathrm{Zi}$ gue-zague.

Uma vez que o (ciber)poema é construído (parte 2), o Zig e o Zag ficam se movimentando na tela como se estivessem nadando e um menu, organizado em duas categorias principais, é disponibilizado ao leitor. Através da palavra início podemos retornar ao começo da animação inicial do ciberpoema, no help temos uma breve instrução sobre como percorrer a história animada. A mudança de cor e tamanho das palavras no menubar (estado), bem como o surgimento de linhas ligando o texto que aparece vinculado às palavras principais, permitem que o navegador oriente-se.

O ponteiro - que indica o ponto de ação ou inserção do usuário com a tela do computador agindo como manipulador virtual e dando o feedback do hipertexto sobre as possibilidades interativas (links) - alterna-se entre seta e mão. Além disso, é utilizado um recurso que não diz respeito à interface gráfica diretamente: o som. Ao passar o mouse sobre o ciberpoema, o som grave do apito de um navio chama a atenção do usuário sobre as possibilidade de entrar por outro mar. Assim, indicando os links, temos o alternar do ponteiro, o som, e ainda três pequenas janelas distintas que se tornam visíveis somente com o passar do mouse sobre elas. São três cenas animadas para onde seremos conduzidos ao clicar do mouse quando, então, a imagem diminuta clicada ocupa toda a janela principal e a narrativa segue frame a frame.

Conforme o que comentamos acima, é possível afirmar que o ciberpoema Ziguezague envolve um nível de interatividade de baixa complexidade, uma vez que é baseado na seleção de respostas por parte dos leitores através do menu de opções e links que não consideram informações dadas pelo usuário em algum momento para propor a ele uma nova situação (opção última que caracteriza um sistema de alta complexidade). Também não temos a possibilidade de comunicação entre usuários ou links externos que nos permitam troca de informações em formato de texto entre diferentes leitores (complexidade intermediária; homem-máquina/homem-homem) (cf. Vittadini, 1995).

Prosseguindo em nossa navegação pelo ciberpoema, veremos que é através da cena 1 que se torna disponível um caminho para a indecisão e o desencontro entre o Zig e o Zag. Uma vez que há um número nominando a cena, podemos dizer que também existe a sugestão do caminho a seguir. Não temos como traçar diferentes destinos às nossas personagens, mas há a possibilidade de avançarmos na sua história, 
percorrendo uma saída para aquilo que o poema impresso havia deixado em aberto. Podemos ver seus encontros e desencontros (cena 1), podemos visualizar suas indagações (cena 2), ou quem sabe vê-los sumir (juntos) no horizonte (cena 3). É possível ir e voltar, repetir quantas vezes quisermos a parte mais interessante, começar do início, recomeçar do meio, mas sua força enquanto narrativa é evidente. Nesse sentido, são pertinentes questões como: essa poesia visual transformou-se em narrativa hipertextual? Há poesia diluída na narrativa? O texto impresso não está fornecendo mais possibilidades de construção de um final para o dilema do Zig e do Zag do que o hipertexto, que costumamos afirmar ser multilinear?

Vemos, portanto, com esse exemplo que nos serve para análise, aquilo que repetidamente discutimos ao abordar a relação linguagem e tecnologia. A hibridação entre ambas gera algo efetivamente novo, diverso do que muitas vezes pareceria o caminho provável proposto pelo seu encontro. O desafio do criador/artista situase em grande parte neste sentido:

\footnotetext{
“Explorar as 'possibilidades' de um sistema significante implica precisamente colocar-se no limite, submeterse à lógica do instrumento, endossar o seu projeto industrial, e o que faz um verdadeiro poeta dos meios tecnológicos é justamente subverter a função da máquina, manipulá-la na contramão de sua produtividade programada." (Machado, 1996: 15)
}

Concentrando agora nossa atenção sobre as imagens em Zigue-zague, observamos as dimensões da proximidade e similaridade (Gestalt) estão evidentes sobretudo naquilo que identificamos como o corpo dos peixes. O uso de uma mesma fonte e sua sobreposição no centro da figura dos peixes são fundamentais para que se tenha a noção do conjunto/corpo. Embora os versos não fechem o contorno das figuras, nossa tendência a continuar de modo racional as formas inacabadas faz com que os percebamos como elipses. Seus encontros e desencontros envolvem a lei do destino comum, quando ao entrarem por lados diferentes e se cruzarem, os vemos como elementos distintos; estando próximos e nadando em uma mesma direção, pareçam formar um só. Os versos "é por aqui", "por aqui não", apesar de terem sido compostos com tipos desencontrados, mantêm uma certa unidade em função de terem cores iguais nas letras que compõem um mesmo verso. Já a diferença de cores (similaridade) entre o sol/ céu e o mar ao final da cena 3 vai estabelecer claramente a divisão entre espaços distintos. O fato de algumas bolhas invadirem o sol gera uma ambigüidade na imagem.

A relação entre imagem e texto, por sua vez, nos possibilita verificar a questão da interdependência entre ambos apontada anteriormente. $\mathrm{Na}$ grande maioria das vezes a linguagem verbal age como contexto principal na interpretação das imagens: encontramos legendas esclarecendo fotografias e elementos gráficos ilustrando dados textuais. No ciberpoema que estamos analisando, podemos visualizar um exemplo disso quando, a partir da cena 1, os versos aparecem centralizados no canto inferior da janela, funcionando como uma legenda para a animação que transcorre acima. Embora os próprios peixes sejam compostos com versos do poema (o primeiro e o último, faltando apenas o intermediário), ressalta-se o caráter imagético dos peixes.

Analisando essa participação do 'leitor', Bettetini diz:

"A interação homem-máquina na computação gráfica coloca-se em uma posição intermediária entre a conversação textual - a qual me referi de maneira apenas geral e que é essencialmente simbólica - e uma troca comunicativa concreta. De fato, de um lado a relação usuário-sistema mantém o caráter simbólico da conversação textual e de outro, porém, ela constitui 
uma possibilidade efetiva de intervenção do usuário, que participa ativamente da produção do sentido do texto." (Bettetini, 1998: 70)

Outra mudança, ressaltada por Bettetini, diz respeito à natureza do enunciador, pois nos textos tradicionais existe uma coincidência entre um saber e um complexo de modalidades definitivamente estruturadas no texto, enquanto que na imagem da computação gráfica essa estruturação e coincidência existem apenas em parte "porque prevalecem, ao invés disso, as estratégias potenciais previstas como opções possíveis do software da máquina e que vêm atualizadas pelas escolhas de intervenção operadas pelo usuário" (Bettetini, 1998:75).

As possibilidades do hipertexto na ciberpoesia vão muito além da convergência de diferentes linguagens. Elas abrem também uma janela para a interatividade, isto é, a participação do navegador no poema, numa interação que tem por base um processo de controle e resposta entre o usuário e o computador (Quéau, 1991; Cotton, 1995; Longhi, 1999).

O ciberpoema Chá mostra algumas dessas possibilidades, estabelecendo uma zona de diálogo com o leitor que, se quiser apreender o poema, deverá agir e reagir e a cada ação/reação recriar um poema novo. Em outras palavras, a xícara inerte na tela do computador requer comandos por parte do navegador para se mostrar. Só então tem-se surpresas inesperadas, como as sonoridades dos ingredientes para o chá ou do bule de cujo bico vertem letras.

Se o navegador se esquece do saquinho de chá, em cuja etiqueta se inscrevem versos do poema, é avisado de que falta alguma coisa e que ele deve prover o necessário para que o poema avance, até que o chá esteja pronto. E onde está a escrita? Na própria fumaça que sai da xícara. Pode se falar que neste ciberpoema, a escrita se dilui na mágica dos movimentos e dos sons e é vista apenas nos vãos das imagens.

O poema escrito aparece cheio de as- sociações de sons e formas. As imagens sem os versos têm uma dimensão poética num sentido amplo, mas sempre será carente do todo; da mesma forma, a escrita continua a construir um poema só que alheio à mágica das diversas linguagens.

\section{A estética dos bites}

Com as novas tecnologias, antigas categorias estéticas estão ameaçadas de desaparecimento. Destas, o princípio fenomenológico da contemplação é a primeira a ser posta em xeque. Não somente na esfera da recepção mas, também, na da produção, antigos hábitos de pensamento mostram-se ineficientes. A prática artística, a estética e a própria noção de obra de arte são despossuídas dos seus conteúdos tradicionais, como também a arte encontra-se em uma encruzilhada. Terá, como Hegel escreveu em meados do século XIX, soado a hora da morte da arte? Certamente que sim, entretanto da arte no seu sentido tradicional. A arte, enquanto expressão da comunidade, da hierarquia das redes do poder e das estruturas do saber.

A técnica participa desta transformação não somente enquanto instrumento, mas como portadora de sentido na obra. Daí o caráter híbrido de muitas das suas realizações. Da união do poema e da imagem surge o poema visual. Híbrido de duas poéticas, a da imagem e a da palavra, conserva em sua tessitura o princípio da representação no sentido estético tradicional. A palavra que a descreve ou analisa é a das categorias estéticas tradicionais.

O ciberpoema, ao abolir a totalidade, explode desde o interior as categorias estéticas tradicionais. Nele, o abandono da noção de totalidade arrasta consigo o princípio da representação. Aí, a relação com a tradição é muito tênue, as categorias tradicionais mostram-se impotentes para descrever ou analisar a sua especificidade. Enquanto objetos, o poema visual e o ciberpoema possuem uma temporalidade própria. 
Como narrativas, são "uma mensagem que enuncia o devir de um sujeito" (Bremond apud Jenny, 1982: 95). Este princípio válido para a lírica, pode ser aplicado ao nosso objeto desde que os pressupostos estejam efetivamente presentes.

O poema visual e o ciberpoema possuem um conteúdo de indeterminação presente no objeto e/ou atribuído pelo leitor. No poema visual ambos estão imbricados, apesar da maior ou menor habilidade do leitor de perceber as ligações; entretanto, elas são finitas pela própria natureza do objeto. Diferentemente do poema visual, o ciberpoema exige um leitor atento e possuidor de habilidades técnicas. Com a interatividade o leitor torna-se co-autor da obra. O preconceituoso postulado da autoria é posto contra a parede. No poema visual, ela pode ser compartilhada. É possível reconhecer níveis de autoria, por exemplo: isto de " $x$ ", aquilo de " $y$ "; ou então: isto de " $x$ " que manipulou " $y$ " que gerou " $\mathrm{z}$ ", manipulado por " $\mathrm{w}$ ". Entretanto, o produto final desta simbiose é o constructo não as suas partes isoladas. No ciberpoema a autoria é coletiva. É possível pensar um ciberpoema em sistema aberto no qual leitores anônimos colaborariam como autores anônimos em uma obra coletiva que, por definição, seria uma obra inacabada, indeterminada, em progresso. Esta possibilidade está vedada ao poema visual pois, por definição, ele mantém a marca, o rastro do objeto de arte tradicional •

\section{Referências}

AARSETH, E. "No linealidad y teoría literaria". In: LANDOW, G. (org.). Teoria del hipertexto. Barcelona: Paidós, 1997, pp. 71-108.

ANDREWS, J. Digital langu(image). Language and image as object in a field. [online] Disponível na internet via URL: http:// wwww.vispo.com/writings/essays/jimartcile.htm Arquivo capturado em $06 / 01 / 00$.

ARNHEIM, Rudolf. Arte e percepção visual. São Paulo: Pioneira,
1996.

AUMONT, J. A imagem. Campinas: Papirus, 1995.

BENJAMIN, Walter. "Einbahnstrasse". In: Gesammelte Schriften. Frankfurt am Main: Suhrkamp, 1980, v IV-1, pp. 83-148.

BETTETINI, G. "Semiótica, computação gráfica e textualidade". In: PARENTE, A. Imagem máquina: a era das tecnologias do virtual. Rio de Janeiro: Editora 34, 1998, pp. 72-88.

BÜRGER, Peter. Theorie der Avantgarde. Frankfurt am Main: Suhrkamp, 1974.

CAMPOS, Augusto de. "Poema, ideograma". In: Mallarmé. São Paulo: Perspectiva, 1974, pp. 181-186.

CAPPARELLI, S. \& LONGHI, R. "Ficção e hipertexto: de Gertrud Stein a Chico Xavier". In: PUCRS, UFRGS, UNISINOS E ULBRA (org). Tendências da Comunicação. Porto Alegre: LPM, 1999, pp. 24-41.

COTTON, B. e OLIVER, R. The cyberspace lexicon: an illustrated dictionary of terms. London: Phaidon, 1994.

DACHY, M. Dada et les dadaísmes: rapport sur l'a néantis-sement de l' ancienne beauté. Paris: Gallimard, 1994.

ECO, U. Obra aberta. São Paulo: Perspectiva, 1986.

GEERTZ, C. The interpretion of cultures. New York: Basic Books, 1977.

GIOVANNINI, J. "A zero degree of graphics". In: FRIEDMAN, M. et allii. Graphic design in America: a visual language history. Minneapolis: Walker Arts Center, 1989, pp. 201-214.

JENNY, L. "O poético e o narrativo". In: 0 discurso da poesia. Coimbra: Almedina, 1982, pp. 95-109.

LANDOW, G. (org) Teoría del hipertexto. Barcelona: Paidós, 1997.

LANDOW, G. Hipertexto. [online] Disponível na internet via URL: http://landow.stg.brown.edu/cpace/ht/htov.html . Arquivo capturado em 15/01/00.

LANDOW, G. Hipertexto. La convergencia de la teoría critica 
contemporánea y la tecnología. Barcelona: Paidós, 1995.

LEMOS, A. Anjos interativos e retribalização do mundo. Sobre interatividade e interfaces digitais. [online] Disponível na internet via URL: http://wwww. facom.ufba.br/pesq/cyber/lemos/ interac.html Arquivo capturado em 08/01/00.

LONGHI, R. "Metáforas e labirintos: a narrativa em hipertexto na Internet". Dissertação de mestrado apresentada no PPGCOM/UFRGS, Porto Alegre, 1999.

MACHADO, A. Máquina e imaginário. São Paulo: Edusp, 1996.

MENEZES, P. "A oralidade no experimentalismo poético brasileiro". In: DOMINGUES, D. A arte no século XXI: a humanização das tecnologias. São Paulo: Unesp, 1998, pp. 272-281.

MENEZES, P. Poesia intersignos. Do impresso an sonoro e ao digital. [online] Disponível na internet via URL: http://wwww.pucsp.br/ cos-puc/epe/mostra/catalogo.htm. Arquivo capturado em 08/01/ 00.

MENEZES, P. Poética e visualidade: uma trajetória da poesia brasileira contemporânea. Campinas: Editora da Unicamp, 1991.

MEYER, C. e DAVIS, S. Blur - The speed of change in the connected economy. New York: Wesley Longman, 1997.

MIRZOEFF, N. An introduction to visual culture. London e New York: Routledge, 1999.

PALÁCIOS, M. Hipertexto [online] Disponível na internet via URL: http://wwww. facom.uffoa.br/pesq/cyber/palacios/hipertexto.html Arquivo capturado em 01/12/99.

PERLOFF, M. O momento futurista: Avant-garde, avant-guerre e a linguagem da ruptura. São Paulo: Edusp, 1993.

PLAZA, J. \& TAVARES, M. Processos criativos com os meios eletrônicos: poéticas digitais. São Paulo: Hucitec, 1998.

PLAZA, J. "As imagens de terceira geração, tecno-poéticas". In: PARENTE, A. Imagem máquina: a era das tecnologias do virtual. Rio de Janeiro: Editora 34, 1998, pp. 72-88.

RICHTER, H. Dadá: arte e antiarte. São Paulo: Martins Fontes, 1993.
SANTAELLA, L. \& NOTH, W. Imagem. Cognição, semiótica e mídia. São Paulo: Iluminuras, 1997.

SANTAELLA, L. A leitura fora do livro. [online] Disponível na internet via URL: http://www.pucsp/ cos-puc/epe/mostra/ santaell.htm Arquivo capturado em 03/01/00.

SANTAELLA, L. "Três paradigmas da imagem". In: OLIVEIRA, A. C. M. \& DE BRITO, Y. C. F. (org.) Imagens técnicas. São Paulo: Hacker Editores, 1998, pp. 167-178.

SOLT, M. Concrete poetry: a world view. [online] Disponível na internet via URL: http://wwww.ubu.com/papers/solt/intro.html. Arquivo capturado em 03/12/99.

VITTADINI, N. "Comunicar com los nuevos media". In: BETTETINI, Gianfranco; COLOMBO, Fausto, Las nuevas tecnologias de la comunicación. Barcelona, 1995.

WAGNER, R “Uber die Benennung 'Musikdrama' ", artigo publicado em 8 de novembro de 1872, no semanário Musikalisches Wochenblatt, [online] Disponível na internet via URL: http://users.utu.fi/hansalmi/texts/benennun.html. Arquivo capturado em 01/12/99.

QUEAU, P. Lo virtual: virtudes y vertigos. Barcelona: Paidós, 1995. 